\title{
Strategies of Developing Rural Tourism Resources from the Perspective of Ecological Protection
}

\author{
Jie Su \\ Guizhou University of Finance and Economics, Guizhou, 550025, China \\ Keywords: rural tourism; countermeasures; cultural ecology \\ Abstract: Culture is the key to improving the quality of tourism. This paper analyzes the \\ current situation and existing problems of China's rural tourism development from the \\ perspective of cultural ecology, and points out that excavating the cultural connotation of \\ rural tourism is the way to improve the quality of rural tourism, and finally put forward the \\ countermeasures for developing rural cultural tourism.
}

\section{Introduction}

With the spring breeze of building a new socialist countryside, the rural tourism in China has developed rapidly. With the implementation of the Qing Ming, Dragon Boat Festival and Mid-Autumn Festival holidays, the leisure activities of urban residents generally choose suburban villages as destinations, providing a rare opportunity for development of rural tourism in rural areas around the city. After a relatively long period of development, rural tourism has evolved from the spontaneous stage to the current conscious stage and has begun to take shape.

\section{The status quo of rural tourism development}

Many rural tourism spots have improved traffic conditions, infrastructure and environmental construction. The overall quality of rural tourism operators and practitioners has been improved, and the level of hygiene and tourism reception has also been greatly improved. As a cultural heritage deeply rooted in different time and space concepts in the human development and human development society, its dynamic nature has become a fresh form of traditional culture, and it has a very rich historical culture in it, and it is also irreplaceable in the development of history. The important value of this is actually very attractive to tourists, and the relevant tourists can also understand and understand the culture through activities. For the inheritance of non-material cultural inheritance, its related national spirit is an important source of development.

\section{Cultural Defects in Rural Tourism Development}

\subsection{The current development of rural tourism resources}

However, many of China's rural tourism projects still remain mostly at the tourist level, and there is less excavation of local culture. To do a little better is to introduce some agricultural knowledge to tourists. The rural tourism products mostly stay in the provision of accommodation and goods for 
farmers. Soil dishes at a low level. Therefore, the cultural quality of these projects is generally low. In addition, rural areas such as viewing rural landscapes, economizing on farming, fruit and flowers, picking harvests, and tasting fresh and delicious foods are all affected by seasonal climate changes, and there will be periods of low seasons, which are detrimental to the development of tourism. With the continuous improvement of the cultural quality of tourists, many tourists will combine tourism with history, literature, art, folk customs, religion, etc., which puts forward higher requirements for rural tourism. Moreover, under the drive of economic interests, the short-term development of tourism development has greatly damaged the humanistic environment in the rural environment. To achieve a sound and sustainable development of rural tourism, it is necessary to focus on the rural humanistic ecology, rely on local resources, explore the richness and nutrition of rural characteristics and local culture, constantly discover and discover the scientific, aesthetic, historical and cultural values of rural areas, and constantly improve rural tourism. The level of science, education, excursions, experience and participation enables tourists to enjoy not only the material and cultural life of the village but also the spiritual and cultural life of the village.

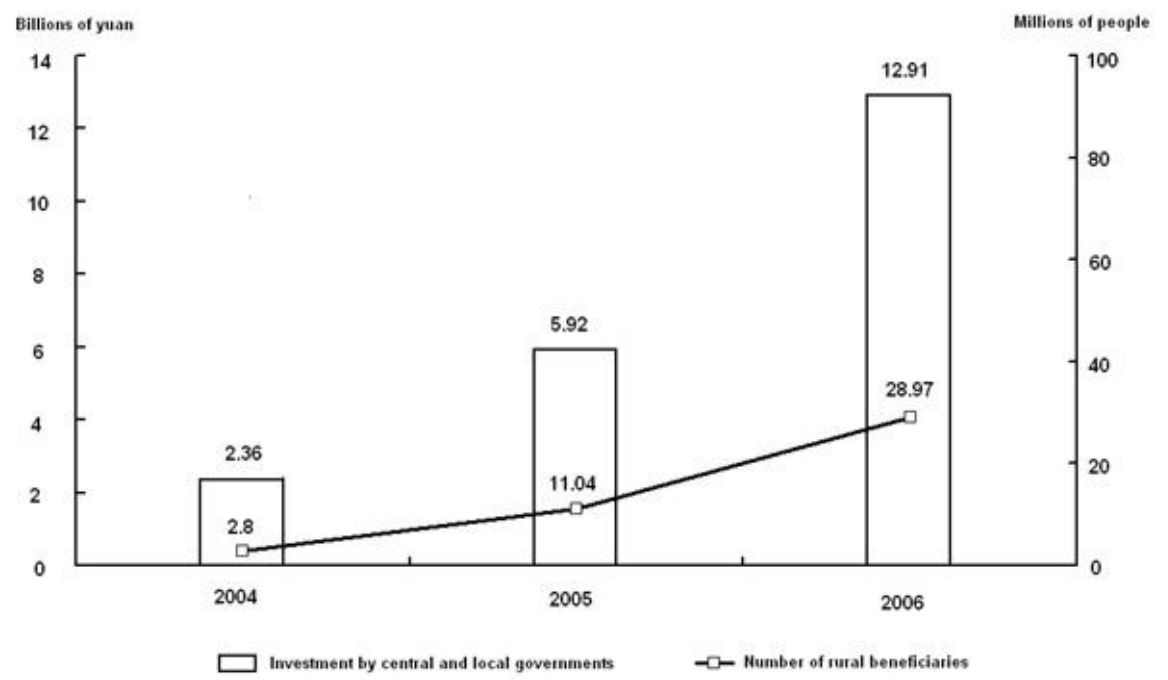

Fig.1 Statistics on rural tourism resources development in recent years

\subsection{Historical Value Analysis}

In the long history of development, different regions and different nationalities will have their own profound cultural traditions, and they will retain their charm in the ever-changing history. After the changes in historical cultural traditions, non-material culture still have a very strong the profound value is reflected in many aspects such as archeology, heritage, spirituality and aesthetics.

\subsection{Educational Tourism and Ecological Protection Value}

Intangible cultural heritage generally has a larger aesthetic value of art. This also shows the different ethnic liveliness in different aspects. The related artistic creativity of the nation has gradually improved. For rural tourism, there are a large number of well-preserved and outstanding works of art. These artistic works are characterized by distinctive characteristics and are highly representative. They are also widely recognized by the people of the contemporary people. To a certain extent, these are also rural areas. Travel tourism develops material basis. Relatively speaking, rural tourism is a kind of social cultural form. This form gives people the power to manage and regulate their own thoughts and behaviors. It also has very important significance for the harmonious development of society. In general, rural tourism contains a lot of ethical and moral 
resources. This is not only a kind of civilization accumulation, but also a guarantee for the stable development of the social order. The process of inheritance and development of non-material cultural heritage is the process of development from a single person to a social group.

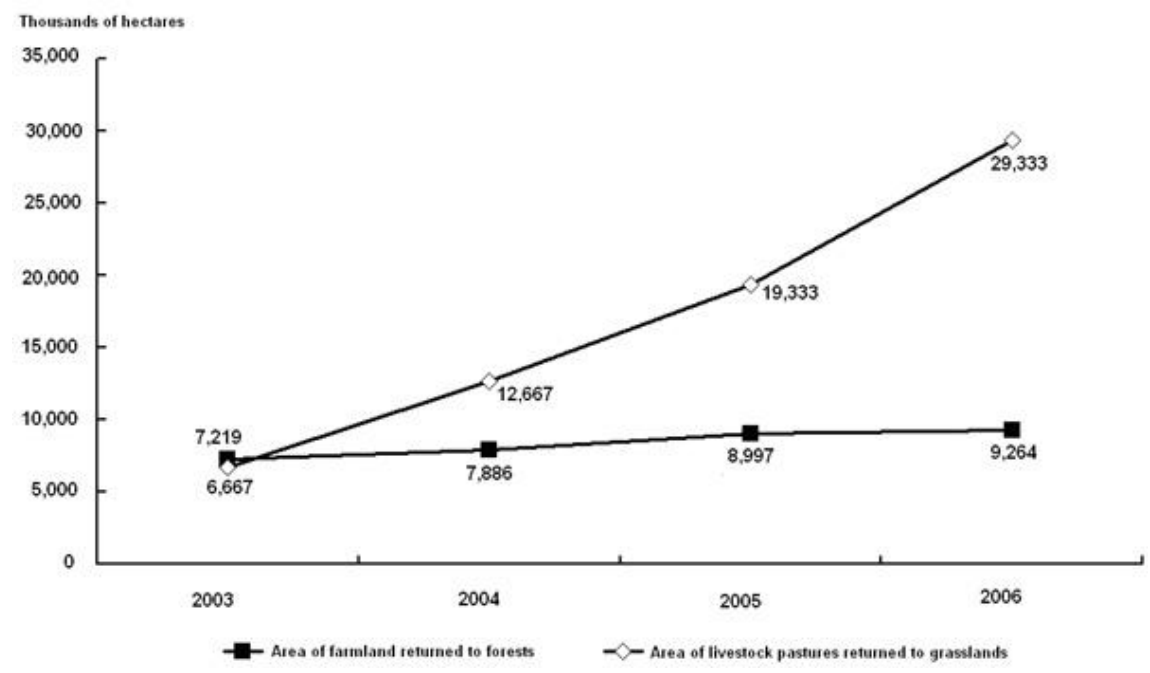

Figure 2 The relationship between rural tourism and ecological protection

\section{Countermeasures for the development of rural cultural tourism}

To improve the taste of rural tourism, it is necessary to dig deeper into its cultural connotations. This will not only increase the quality of tourism experience for tourists, but also protect and develop tourism cultural resources, and it is also very beneficial to the sustainable development of tourism destinations.

\subsection{Differentiated Development}

Excavating local unique cultural resources and highlighting the characteristics of local tourism resources are the most important principles in the development of tourism resources. To survive, develop, and produce color, rural tourism must pursue uniqueness, assert individuality, and give full play to its unique advantages. On the other hand, the more culturally rich and distinctive the individual characteristics, the more attractive the tourism in the region is. However, in the process of pursuing characteristics, it is not possible to "excavate" the connotations of historical dignity in a far-fetched manner, interfere with the sacred mood of religious culture with realistic utilitarian demands, and subvert the heavy and innocent folk culture with a vulgar vision. It requires developers to first correctly understand the unique characteristics of local cultural tourism resources, such as the history of the formation, the wisdom of production, and the distinctive tendencies. Nowadays, the homogenization of rural tourism products has become more and more fierce. Different cultural tourism products have become an important means to enhance competitiveness. The characteristic is that rural tourism avoids vicious competition and achieves sustainable development.

\subsection{Coordinated Protection and Development In the process of the protection of cultural heritage, funding problems often arise.}

Due to the need to invest sufficient funds in development and development, the funds invested in protection are often insufficient. In fact, these two aspects of contradiction can be unified in the 
development of rural tourism. The rural cultural heritage is well protected and has local characteristics, which can increase the attractiveness of rural tourism and thus promote the development of rural tourism. By using the engineering PRB calculation concept for resource utilization, it can be used for reference to the development and utilization of rural resources:

$$
\text { CQI_Per_ Frame } \text { PRB }_{\text {_ }}
$$

In addition, roads, houses, and toilets built for the development of rural tourism in some places are severely urbanized in style and disharmonious with the rural environment.

\subsection{The combination of cultural experience and material experience}

With the advent of the experience economy, people are increasingly paying attention to the improvement of the quality of tourism experience. In the process of the development of rural cultural tourism, the affinity of rural culture should be enhanced so that tourists can participate in local life in varying degrees, be close to the local traditional culture, and be immersed in the influence of local culture. Tourists will naturally increase their enjoyment. The understanding of local native culture is also more thorough.

\section{Summary}

Transforming and exchanging traditional culture, transforming the advantages of rural culture into advantages of tourism economy, transforming potential advantages into practical advantages, and building a new culture based on this, so as to better promote the sustainable development of rural tourism. We will properly handle the relationship between conservation and use of natural and human ecology, folklore and cultural heritage, take into account current and long-term interests, and realize the joint improvement of the economic, social, and cultural benefits of rural tourism so that rural tourism can be improved in Continuous development.

\section{References}

[1] Juan X U. Studies on Rural Ecological Tourism in Hengyang from the Perspective of Modern Ecological Civilization [J]. Journal of Central South University of Forestry \& Technology, 2015.

[2] Wang X Y. Proposal for Sustainable Development of China Rural Tourism from the Perspective of Ecological Civilization [J]. Journal of Central South University of Forestry \& Technology, 2016.

[3] Wang Z P, University K. Rural Tourism Development in Henan under the Perspective of the Construction of Ecological Civilization [J]. Journal of Kaifeng University, 2016. 